2 Cortese S, Faraone SV, Konofal E, Lecendreux M. Sleep in children with attention-deficit/hyperactivity disorder: meta-analysis of subjective and objective studies. J Am Acad Child Adolesc Psychiatry. 2009;48: 894-908.

3 Brasil HHA. Desenvolvimento da versäo brasileira da K-SADS-PL (Schedule for Affective Disorders and Schizophrenia for Scholl Aged Children Present and Lifetime Version) e estudo de suas propriedades psicométricas [thesis]. São Paulo: Universidade Federal de São Paulo; 2003.

4 Cortese S, Brown TE, Corkum P, Gruber R, O'Brien LM, Stein M, et al. Assessment and management of sleep problems in youths with attention-deficit/hyperactivity disorder. J Am Acad Child Adolesc Psychiatry. 2013;52:784-96.

5 Lauderdale DS, Knutson KL, Yan LL, Liu K, Rathouz PJ. Sleep duration: how well do self-reports reflect objective measures? The CARDIA Sleep Study. Epidemiology. 2008;19:838-45.

6 Hiscock H, Sciberras E, Mensah F, Gerner B, Efron D, Khano S, et al. Impact of a behavioural sleep intervention on symptoms and sleep in children with attention deficit hyperactivity disorder, and parental mental health: randomised controlled trial. BMJ. 2015; 350:h68.

\section{Organic psychosis due to hypoparathyroidism in an older adult: a case report}

Rev. Bras. Psiquiatr. 2016;38:349-350

doi:10.1590/1516-4446-2015-1869

We present a case of psychosis secondary to iatrogenic hypoparathyroidism and hypocalcemia in a 73-year-old woman. At age 18, she had undergone a total thyroidectomy and developed severe psychotic symptoms due to unintended removal of the parathyroid glands, but had recovered fully after a hospital stay. For the last 15 years, she had been receiving periodic psychiatry follow-up for mild depressive and psychotic symptoms, consisting of auditory hallucinations (children's voices calling her "Mommy"). For years, she had been stable on a combination of fluoxetine $20 \mathrm{mg} /$ day and olanzapine $10 \mathrm{mg} /$ day. She had worked as a nurse with no functional impairment until retirement at age 65 .

The patient presented to the emergency department reporting anguish, auditory hallucinations of male voices that insulted her (which, according to the patient, came from electronic devices), and auditory misperceptions, with intolerance to electronic noises. The situation had worsened in the previous 6 months, and the patient now exhibited marked social withdrawal. She also presented a secondary depressed mood.

She was admitted to the psychiatric department. Initial treatment was olanzapine $10 \mathrm{mg} /$ day, with no therapeutic response. The patient crawled into the observation bay, stating the noise of the air conditioner was unbearable. Ten days after admission, olanzapine was stopped and risperidone $2 \mathrm{mg} /$ day and mirtazapine up to $30 \mathrm{mg} /$ day were introduced. Her condition improved, but she conti- nued to report hearing voices, although more bearable. She was discharged to the day hospital for diagnostic clarification.

The patient was found to have a mild ataxic gait worsened by extrapyramidal symptoms, with no clear improvement despite anticholinergic therapy. No other neurological signs of hypocalcemia were found. Blood tests showed hypocalcemia, hyperphosphatemia, and mild hypoparathyroidism (Table 1). A severe vitamin $D$ deficiency was also noticed (Table 1). We noticed that the patient had been refusing to take the calcium and calcitriol supplementation prescribed by her endocrinologist, leading to chronic hypocalcemia. Computed tomography scans showed bilateral calcifications in the globi pallidi and cerebellar dentate nuclei (Figure 1). Neuropsychological assessment showed mild cognitive impairment in some areas (attention/concentration, verbal initiative, and motor function).

Additional calcium supplementation was prescribed (calcium carbonate $4,000 \mathrm{mg}$ daily) and calcitriol was reintroduced ( $0.25 \mu \mathrm{g}$ twice daily), with subsequent improvement in laboratory values (Table 1). The patient's ataxic gait became barely perceptible and her auditory hallucinations, although persistent, became quieter and more bearable, with no interference with function or behavior. Accordingly, her secondary depressed mood improved to euthymia. Interestingly, motor function and attention, which were impaired at the first neuropsychological assessment, also improved after calcium and calcitriol supplementation. Symptomatic treatment of psychosis with risperidone $2 \mathrm{mg} /$ day was reduced to $1 \mathrm{mg} /$ day and later switched to paliperidone $3 \mathrm{mg} /$ day due to intolerable extrapyramidal symptoms. No worsening was noticed after the dose reduction and switch in antipsychotic agent.

Few cases of hypoparathyroidism and hypocalcemia with neuropsychiatric manifestations have been reported. ${ }^{1,2}$ Basal ganglia calcification involving the globus pallidus and cerebellum is typical, perhaps due to hyper-

Table 1 Blood test results at admission and after 6 months of calcium and vitamin D supplementation

\begin{tabular}{|c|c|c|c|}
\hline & \multicolumn{2}{|c|}{ Value } & \multirow[b]{2}{*}{ Normal range } \\
\hline & Admission & Follow-up & \\
\hline lonized calcium (mmol/L) & 0.84 & 1.24 & 1.13-1.32 \\
\hline Phosphorus (mmol/L) & 5.40 & 4.3 & $2.70-4.5$ \\
\hline Magnesium (mmol/L) & 0.68 & 0.80 & $0.78-1.02$ \\
\hline Parathyroid hormone $(\mathrm{pg} / \mathrm{mL})$ & 8.40 & 9.40 & $10-55$ \\
\hline Vitamin D $(\mathrm{ng} / \mathrm{mL})$ & 13 & 27 & $>30$ \\
\hline
\end{tabular}



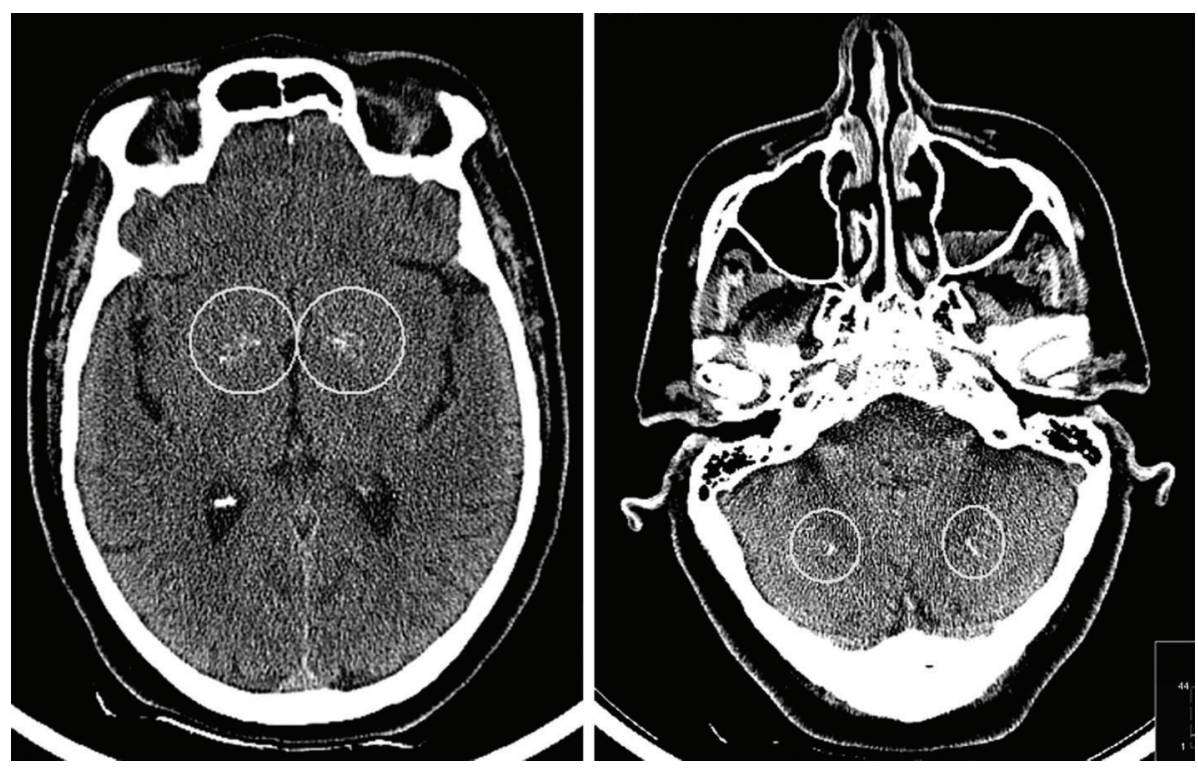

Figure 1 Axial computed tomography scans of the head showing calcifications in the globi pallidi (left) and dentate nuclei (right).

phosphatemia, resulting in psychosis, mood disorders, or both, as well as neurological manifestations. The basal ganglia play important roles in mood, cognition, motivation, and motor control; their function includes motor learning, attention allocation and filtering, and working memory. Psychotic symptoms in such cases often include auditory hallucinations, delusions of influence, paranoid states, and complex perceptual distortions. ${ }^{3}$ Hypocalcemia also causes cognitive impairment. Neurological manifestations tend to improve with calcium correction, but psychiatric symptoms do not improve substantially. ${ }^{4}$

We believe this case report illustrates the need for an exhaustive workup of possible organic etiologies when psychiatric patients present with atypical symptoms. All symptoms presented by the patient could be explained by her hypoparathyroidism, hypocalcemia, and consequent typical brain calcifications, justifying the diagnosis of organic psychosis. In addition, vitamin D deficiency may worsen psychotic symptoms. ${ }^{5}$

Ana D. Amaral, ${ }^{1}$ Catarina Novais, ${ }^{1}$ Maria A. Coelho, ${ }^{1,2}$ Alzira Silva, ${ }^{1,3}$ Rosário Curral, ${ }^{1,3}$ Isabel Brandão, ${ }^{1,3}$ António R. Torres ${ }^{1}$

${ }^{1}$ Clínica de Psiquiatria e Saúde Mental, Centro Hospitalar de São João, Porto, Portugal. ${ }^{2}$ Departamento de Farmacologia e
Terapêutica, Faculdade de Medicina, Universidade do Porto, Porto, Portugal. ${ }^{3}$ Departamento de Neurociências, Faculdade de Medicina, Universidade do Porto, Porto, Portugal.

Submitted Nov 28 2015, accepted May 162016.

\section{Disclosure}

The authors report no conflicts of interest.

\section{References}

1 Finan M, Axelband J. This is your brain on calcium: psychosis as the presentation of isolated hypoparathyroidism. Am J Emerg Med. 2014 32:945.e1-4.

2 Ang AW, Ko SM, Tan $\mathrm{CH}$. Calcium, magnesium, and psychotic symptoms in a girl with idiopathic hypoparathyroidism. Psychosom Med. 1995;57:299-302.

3 Burns K, Brodaty H. Fahr's disease and psychosis. In: Sachdev PS, Keshavan MS, editors. Secondary schizophrenia. Cambridge: Cambridge University; 2010. p. 358-66.

4 Maiti A, Chatterjee S. Neuropsychiatric manifestations and their outcomes in chronic hypocalcaemia. J Indian Med Assoc. 2013; 111:174-7.

5 Amaral AD, Calhau C, Coelho R. Schizophrenia: implications of vitamin D deficit on brain development. IJCNMH. 2014;1:1-14. 